Article

\title{
Experimental Study on Dynamics of Wooden House Wall Panels with Different Thermal Isolation
}

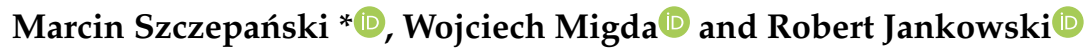 \\ Faculty of Civil and Environmental Engineering, Gdansk University of Technology, 80-233 Gdansk, Poland; \\ wmigda@pg.edu.pl (W.M.); jankowr@pg.edu.pl (R.J.) \\ * Correspondence: marszcze@pg.edu.pl
}

Received: 4 August 2019; Accepted: 14 October 2019; Published: 17 October 2019

\begin{abstract}
Wood frame buildings are very popular in regions that are exposed to different dynamic excitations including earthquakes. Therefore, their seismic resistance is really important in order to prevent structural damages and human losses. The aim of the present paper is to show the results of experimental tests focused on the dynamic response of wall panels of a wooden frame building with thermal isolation made of mineral wool and polyurethane foam. Firstly, the static and the dynamic mechanical analysis (DMA) tests were conducted so as to determine the basic thermomechanical properties of the analyzed isolation materials. Then, the elements of the exterior walls with two types of thermal insulation were tested under harmonic excitation for different amplitudes of displacement. The results of the static material tests indicate that the polyurethane foam behaves in a highly nonlinear way both during compression and tension. Moreover, the results of the DMA tests show that the storage and loss modulus of the polyurethane foam are significantly larger in relation to the values obtained for the mineral wool. The results of the dynamic tests on wall panels show that the use of polyurethane foam as thermal isolation leads to a substantial increase in stiffness and damping properties, as compared to the case when the mineral wood is used.
\end{abstract}

Keywords: wood-frame buildings; seismic resistance; thermal insulation; polyurethane foam; mineral wool

\section{Introduction}

The seismic resistance of civil engineering structures, especially buildings, is an important aspect related to structural safety in the event of an earthquake [1-3]. Damages to building structures are the most common cause of fatalities due to seismic excitation. This applies to structures erected with different technologies.

Buildings of major importance, such as hospitals, facilities of fire brigades or crisis management centres are designed in accordance with the applicable standards [4]. Methods of strengthening these structures, mainly constructed of reinforced concrete or steel frame (for example using the fiber-reinforced cementitious composite [4]), are subjected to many tests, including experimental and numerical ones [5-9]. There are many methods of retrofitting masonry structures, including methods for strengthening cracked walls using high-strength composite materials and a rigid adhesive with low deformability [10-14]. The concept of increasing the effectiveness of secondary structural elements in the overall seismic behaviour of buildings has also been investigated; for example, the application of special mechanical connectors interposed at the interface between a multi-storey building and the glazing facade [15]. The results of the study indicate that, once the input parameters of the connecting devices are properly designed, the glazing facade may work as an effective passive control system for the primary structure [15]. 
An increasing number of newly constructed wooden frame buildings has also been recently observed. The technology is popular both in rich and poor countries. Properly designed wooden structures are inherently well resistant to dynamic loads, such as extreme earthquakes [16]. The current research concerning wooden buildings is focused, among others, on forecasting the occurrence of damage and monitoring the critical structural elements during seismic shocks $[17,18]$. The research work includes both experimental investigations, including the shaking table tests (see $[19,20])$, as well as numerical analyses. A number of studies have been focused on structural connectors, anchor connections and special flat bars and angles, the use of which results in stiffening of the whole structure and increasing its seismic resistance [21-23]. The role of connections, with the lateral deformation of the light walls and with q-factor, has also been investigated (for example, see [24-28]).

In addition, the low construction cost is one of the most popular and well-known advantages of wooden buildings. This is due to the relatively good availability of building material in many parts of the world and ease of assembly related to technical aspects (heavy equipment is not required), as well as assembly time and good usability parameters (aesthetics, easy repairs and modifications, good climate, etc.). However, one of the most important technological elements in a wooden frame is the application and proper arrangement of thermal insulation. Thermal insulation affects the lifespan and durability of the building, and defines the energy class [29]. Unlike other elements of a wooden frame building, the results of research focused on thermal insulation are relatively limited. One of a few examples concerns a study on the seismic efficiency of structural insulated panels [30]. The behaviour of wood-composite laminated frames under the dynamic loads has also been investigated [31].

There are some numerical analyses available, which indicate that thermal insulation of the wooden frame building can substantially affect the dynamic resistance of the whole structure (for example, see $[32,33])$. The results of these analyses show that using polyurethane foam instead of mineral wool for the in-wall insulation of a wood-frame building leads to an increase in the rigidity of the whole structure. This effect is obtained mainly due to full connection between the polyurethane foam and the surrounding wooden elements, and a lack of such connection in the case of mineral wool. It has been found that the increase in the rigidity of the building insulated with the polyurethane foam leads to the substantial reduction in the structural response under different seismic excitations [33]. It should be added that, in construction, polyurethane foam is known only as an insulation material. It turns out that this insulation material can also effectively stiffen the whole structure and improve its dynamic resistance substantially. However, the results of the numerical analyses described in $[32,33]$ have to be verified experimentally.

Therefore, the aim of the present study is to show the results of experimental tests focused on the dynamic response of wall panels of a wooden frame building with thermal isolation made of traditional mineral wool and polyurethane foam. Firstly, the static and the dynamic mechanical analysis (DMA) tests were conducted so as to determine the basic thermomechanical properties of the analyzed isolation materials. Then, the elements of exterior walls with two types of thermal insulation were tested under harmonic excitation for different amplitudes of displacement.

\section{Static Material Tests}

Firstly, static compression and tension tests were carried out for the polyurethane foam (because of the mechanical parameters of mineral wool and the problem with fixing the samples, tests for this material were not possible). The tests were conducted using a two-column Zwick/Roell Z020 machine with a maximum force range of $20 \mathrm{kN}$.

Polyurethane foam static compression tests were carried out on a number of cylindrical samples with a cross-section area of $18 \mathrm{~mm}^{2}$ and a height of $20 \mathrm{~mm}$ (Figure 1). Material samples were taken directly from the wall panels of the wooden frame building, which were previously tested experimentally (see Section 4). The representative results of the static compression tests, in the form of relation between stress and strain, are shown in Figure 2. It should be added that nearly identical curves were obtained for all of the tested samples and the scatter of the results was negligibly small. 
It can be seen from Figure 2 that the foam behaves in a highly nonlinear way during compression. In the range of elongation from 0 to about 0.1 , stresses increase up to about $250 \mathrm{kPa}$. Then, at the deformation above about 0.1 , stabilization occurs, and above this range of strains, the stresses remain almost constant.

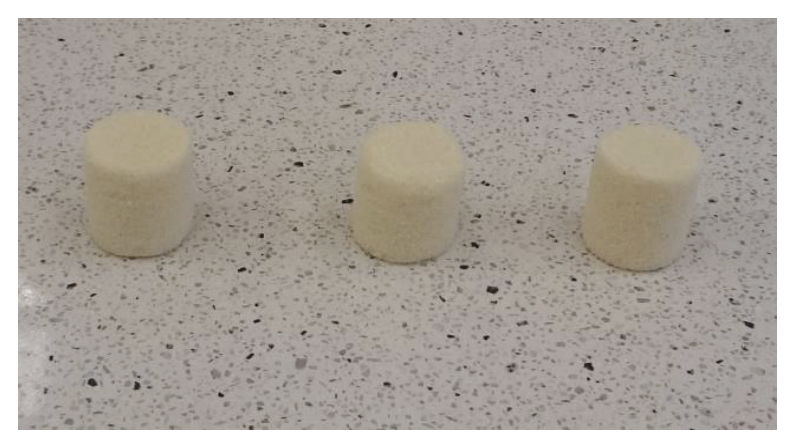

Figure 1. Samples made of polyurethane foam subjected to static compression.

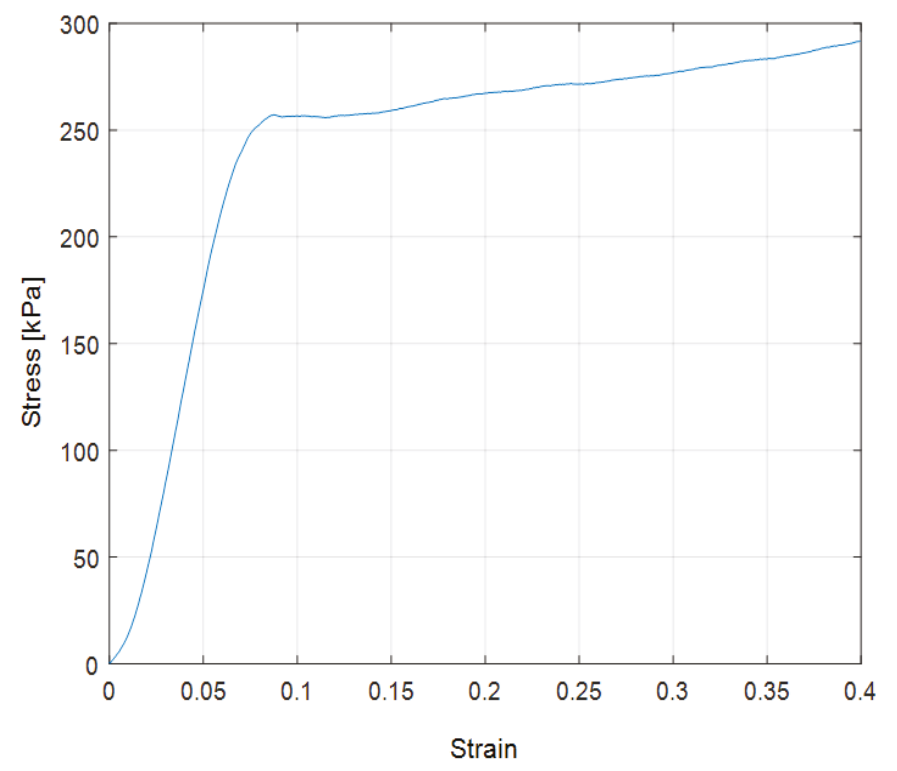

Figure 2. Relation between stress and strain for polyurethane foam subjected to static compression (average of tested specimens).

Polyurethane foam static tension tests were carried out on a number of samples with a cross-section of $10 \mathrm{~mm}^{2}$ and a height of $80 \mathrm{~mm}$ (Figure 3). Material samples were taken directly from the wall panels of the wooden frame building, which were previously tested experimentally (see Section 4 ). The representative results of the static tension tests, in the form of relation between stress and strain, are shown in Figure 4. It should be added that nearly identical curves were obtained for all of the tested samples and the scatter of the results was negligibly small. It can be seen from Figure 4 that the foam behaves in a highly nonlinear way also during tension. In the strain range from 0 to about 0.05 , the stresses increase nonlinearly up to about $43 \mathrm{kPa}$. In the strain interval above 0.05 , the stresses increase almost linearly to the level of about $105 \mathrm{kPa}$. 


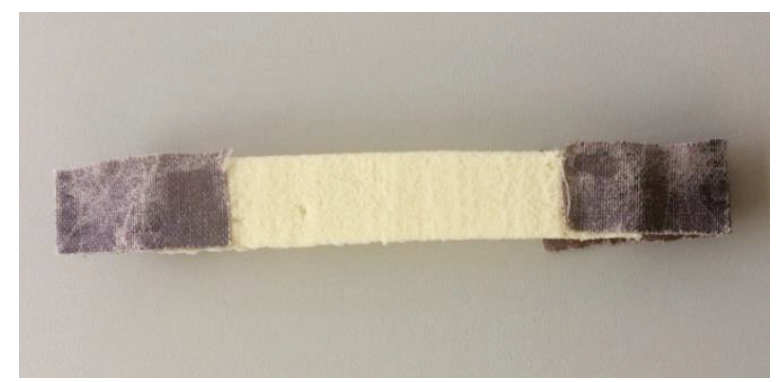

Figure 3. A sample made of polyurethane foam subjected to static tension.

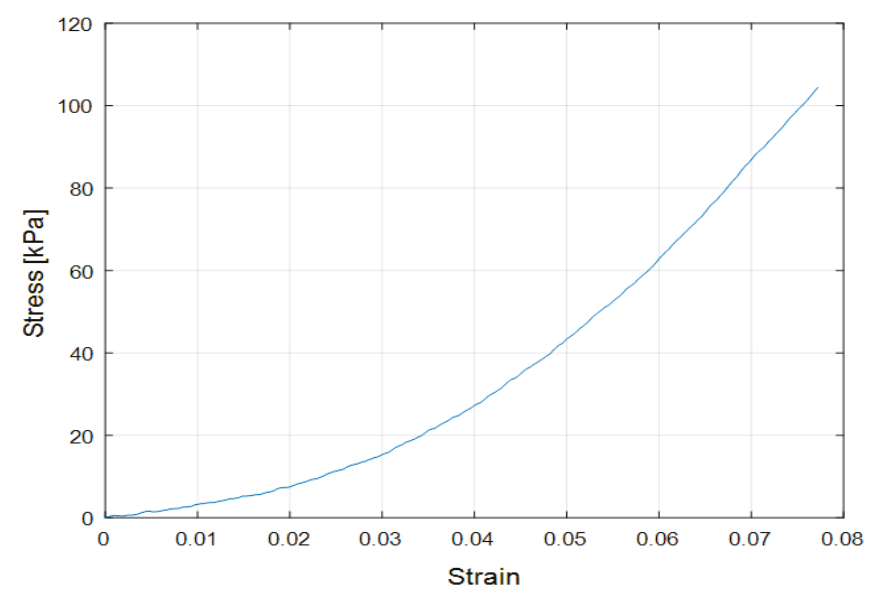

Figure 4. Relation between stress and strain for polyurethane foam subjected to static tension (average of tested specimens).

\section{DMA Material Tests}

In the second stage of investigation, dynamic mechanical spectroscopy tests were performed using the DMA Q800 Instruments apparatus (Figures 5 and 6). The parameters of tests are presented in Table 1. It should be underlined that the range of temperatures and frequencies corresponded to real conditions. The loading protocol was taken according to standards ASTM D4092 and DIN 53440.
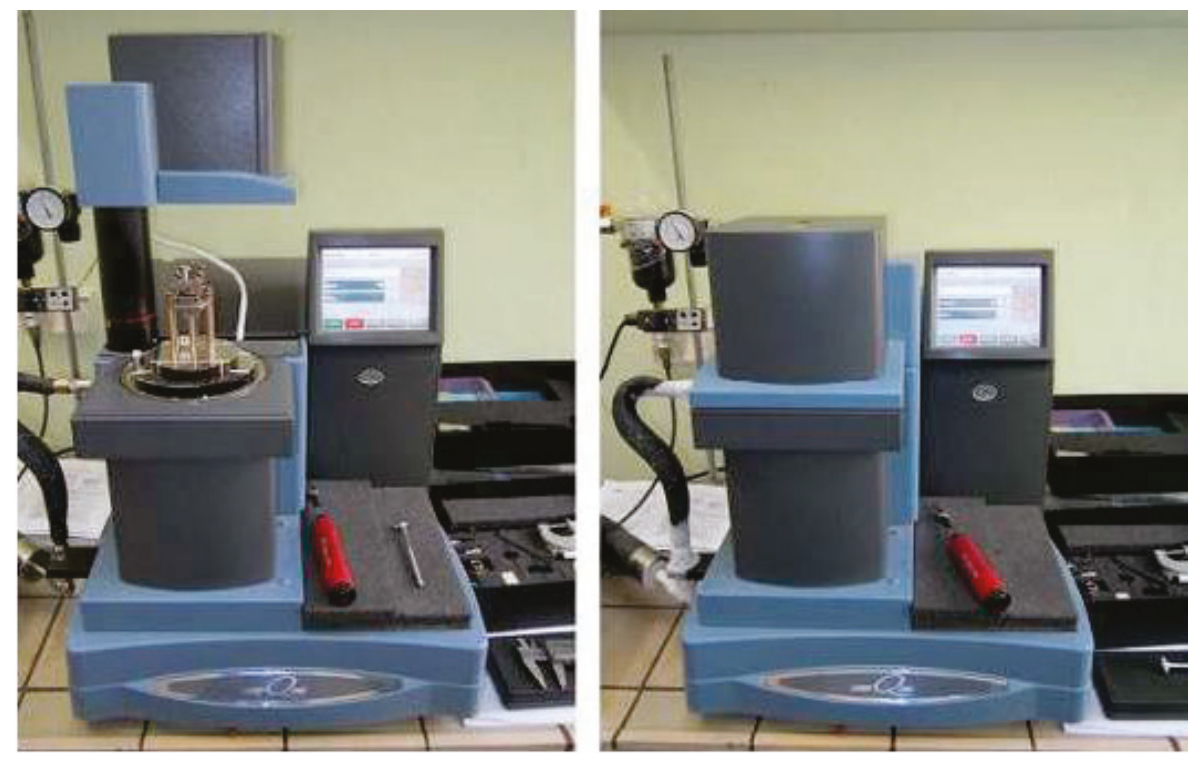

Figure 5. Test setup with dynamic mechanical analysis (DMA) Q800 analyzer. 


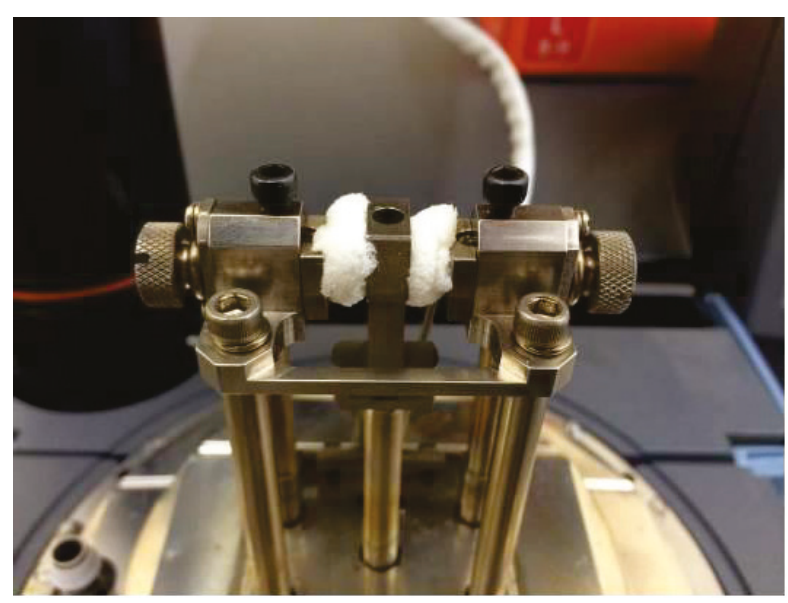

Figure 6. Mounting of polyurethane foam in DMA Q800 analyzer.

Table 1. Parameters of DMA tests.

\begin{tabular}{cc}
\hline Parameter & Specification \\
\hline Dimensions of the test sample & Cylinder with a height of $10 \mathrm{~mm}$ and a diameter of $12 \mathrm{~mm}$ \\
Frequency range & From $1 \mathrm{~Hz}$ to $20 \mathrm{~Hz}$ \\
Heating speed & $4{ }^{\circ} \mathrm{C} / \mathrm{min}$ \\
Temperature range & From $-30^{\circ} \mathrm{C}$ to $+50^{\circ} \mathrm{C}$ \\
\hline
\end{tabular}

The results of the DMA tests (compression tests) are presented in Figures 7-14 and are summarized in Tables 2 and 3. The results show the change of storage modulus, loss modulus and loss factor (tan delta) as the temperature increases. It should be mentioned that the storage modulus measures the stored energy in the material due to the applied strain and represents the elastic portion of energy [34]. On the other hand, the loss modulus measures the energy dissipated through molecular motion and represents the viscous portion of energy. The ratio of the loss modulus to storage modulus is termed as the loss factor [34].

The results of DMA tests (see Figures 7-14) clearly show that the values of storage and loss modulus were substantially larger for the polyurethane foam, as compared to the mineral wool. In particular, it can be seen from Tables 2 and 3 that, for the case of the temperature of $20^{\circ} \mathrm{C}$, the storage modulus of the polyurethane foam was larger by as much as $91.7 \%, 76.8 \%$ and $77.4 \%$ for the frequencies of $1 \mathrm{~Hz}, 10 \mathrm{~Hz}$ and $20 \mathrm{~Hz}$, respectively. In turn, the loss modulus of the polyurethane foam was bigger than the corresponding value for the mineral wool by as much as $61.4 \%, 74.5 \%$ and $88.3 \%$ for the frequencies of $1 \mathrm{~Hz}, 10 \mathrm{~Hz}$ and $20 \mathrm{~Hz}$, respectively. This indicates that the polyurethane foam, as a material, was able to dissipate a larger amount of energy. Therefore, comparing it to the mineral wool, it is a material with much better absorption capabilities related directly to the energy absorption. 


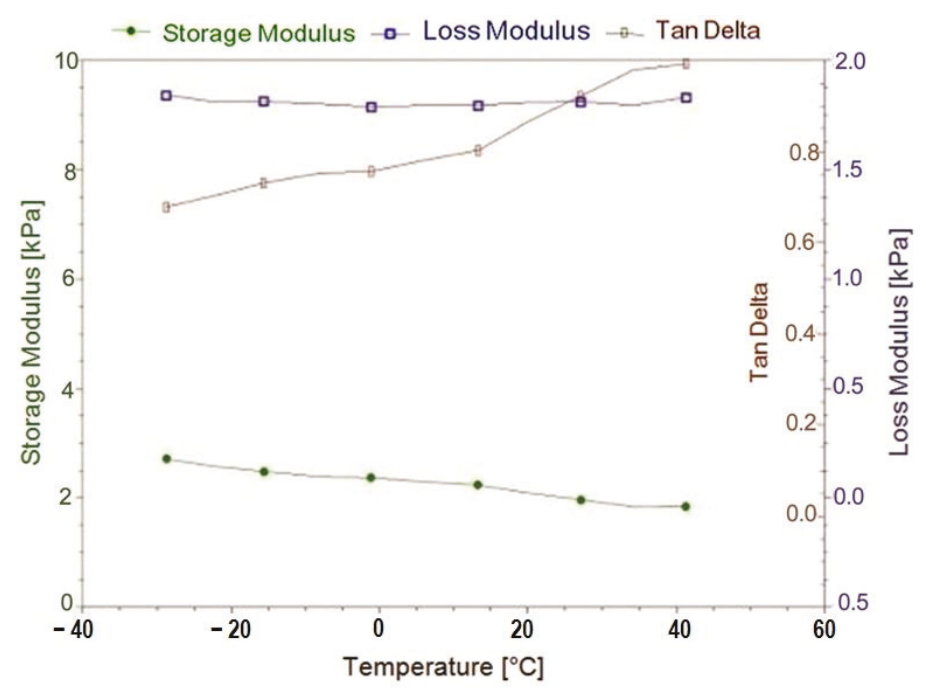

Figure 7. Results of DMA tests for mineral wool for frequency $1 \mathrm{~Hz}$.

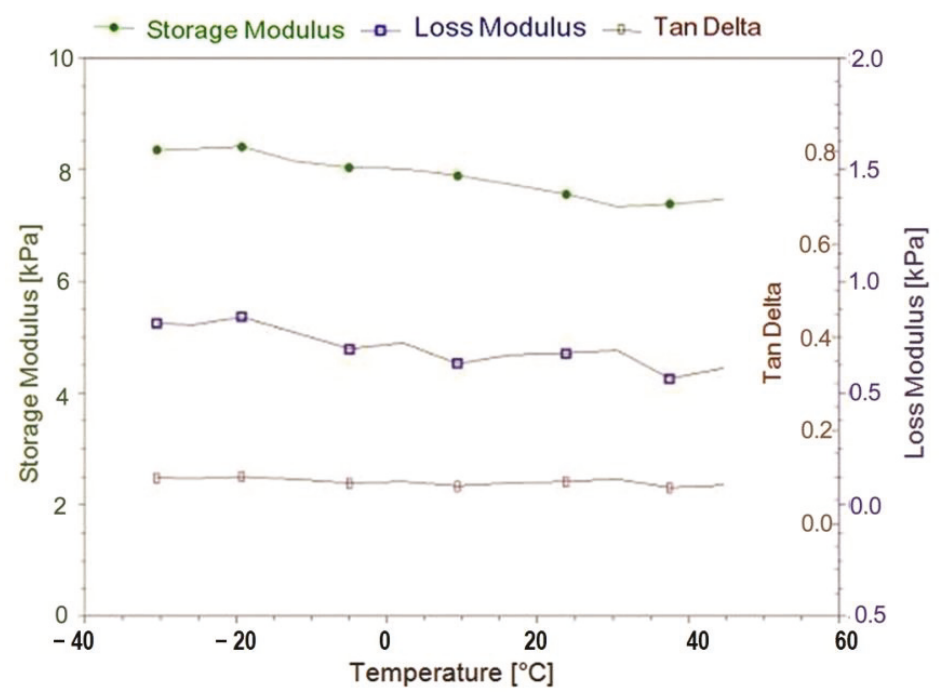

Figure 8. Results of DMA tests for mineral wool for frequency $10 \mathrm{~Hz}$.

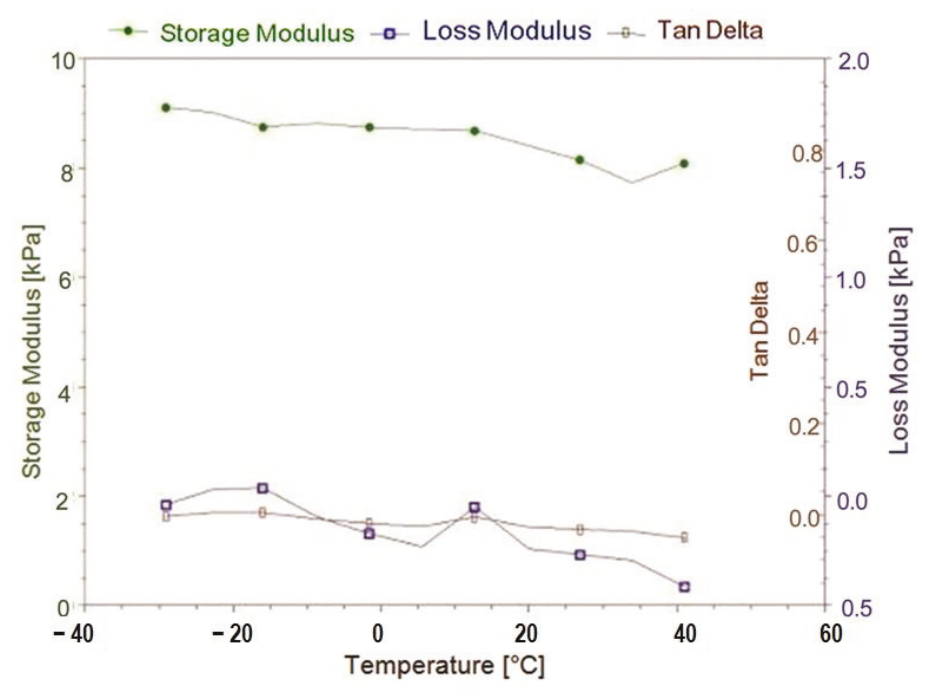

Figure 9. Results of DMA tests for mineral wool for frequency $20 \mathrm{~Hz}$. 


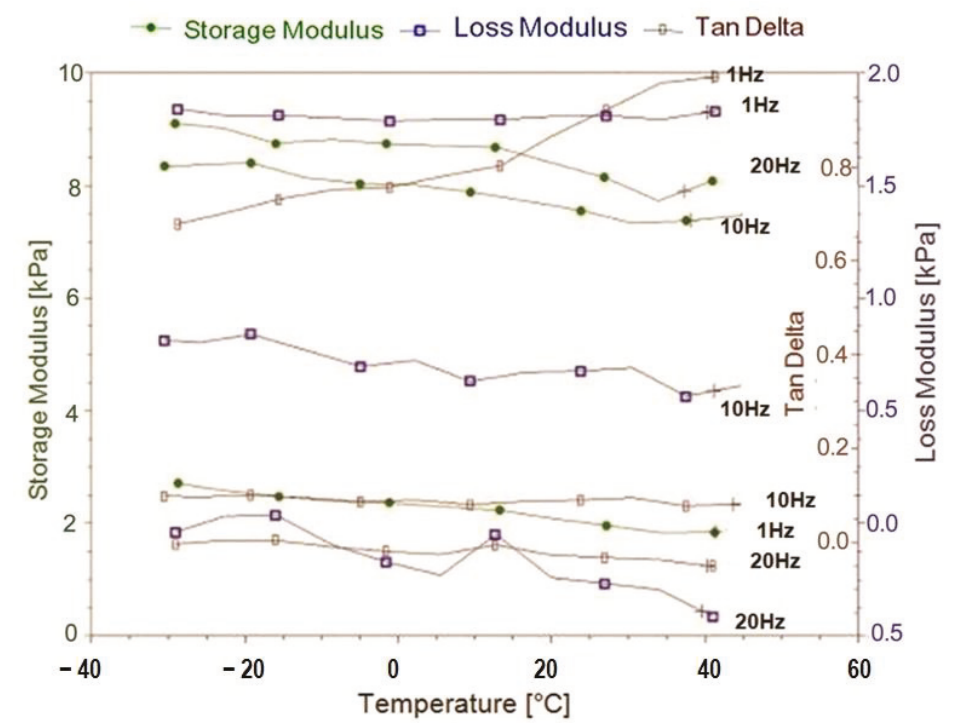

Figure 10. Results of DMA tests for mineral wool; comparison for all frequencies analyzed.

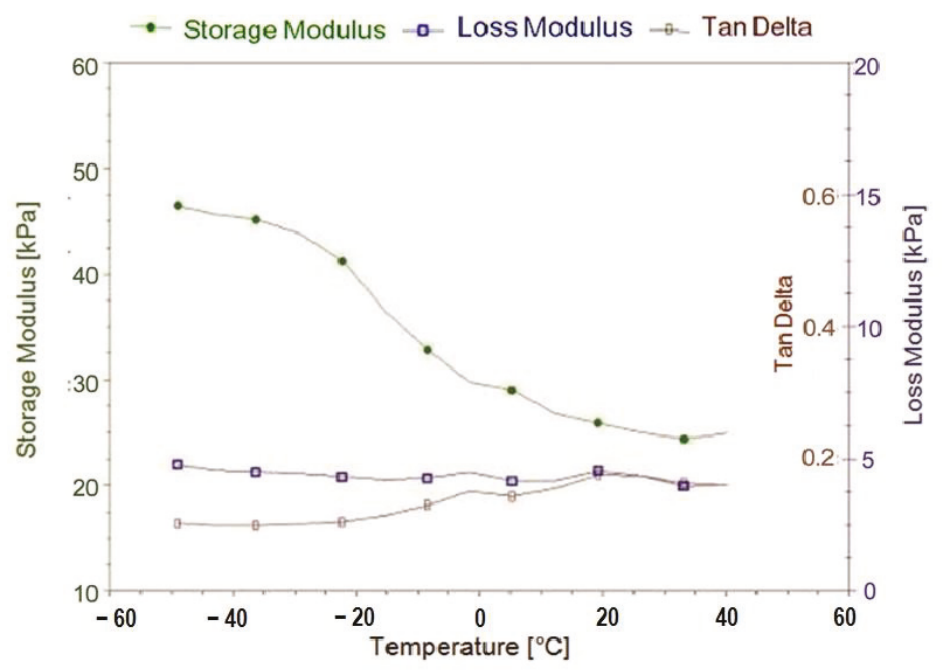

Figure 11. Results of DMA tests for polyurethane foam for frequency $1 \mathrm{~Hz}$.

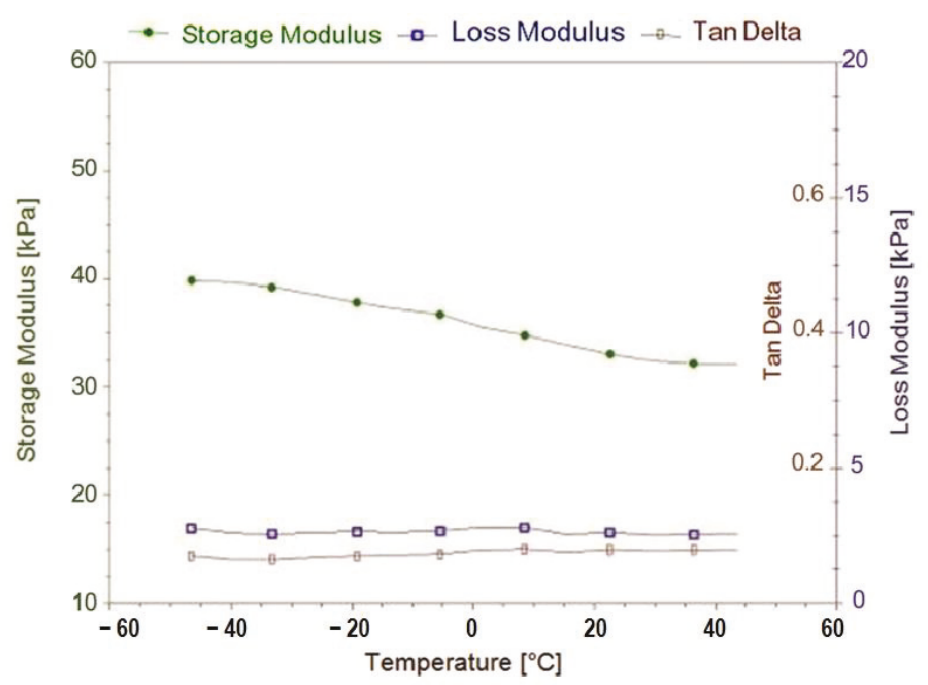

Figure 12. Results of DMA tests for polyurethane foam for frequency $10 \mathrm{~Hz}$. 


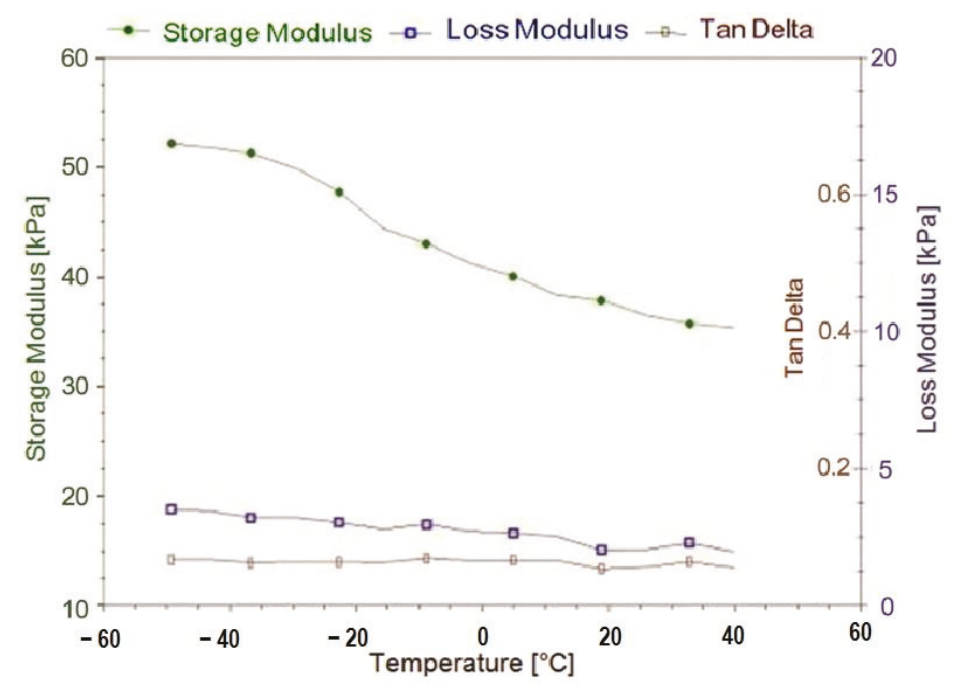

Figure 13. Results of DMA tests for polyurethane foam for frequency $20 \mathrm{~Hz}$.

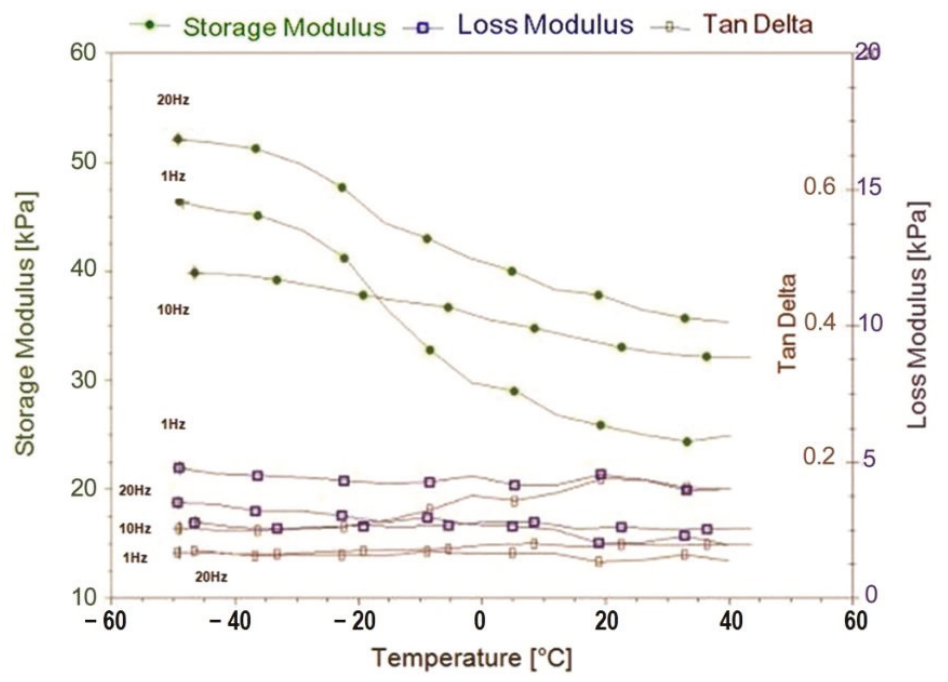

Figure 14. Results of DMA tests for polyurethane foam; comparison for all frequencies analyzed.

Table 2. Summary of DMA tests results for mineral wool for temperature of $20^{\circ} \mathrm{C}$.

\begin{tabular}{cccc}
\hline Frequency $[\mathrm{Hz}]$ & Storage Modulus $[\mathrm{kPa}]$ & Loss Modulus $[\mathrm{kPa}]$ & Tan Delta \\
\hline 1 & 2.10 & 1.81 & 0.86 \\
10 & 7.65 & 0.65 & 0.10 \\
20 & 8.45 & 0.25 & 0.025 \\
\hline
\end{tabular}

Table 3. Summary of DMA tests results for polyurethane foam for temperature of $20^{\circ} \mathrm{C}$.

\begin{tabular}{cccc}
\hline Frequency $[\mathrm{Hz}]$ & Storage Modulus [kPa] & Loss Modulus [kPa] & Tan Delta \\
\hline 1 & 25.55 & 4.70 & 0.175 \\
10 & 33.00 & 2.55 & 0.07 \\
20 & 37.50 & 2.15 & 0.055 \\
\hline
\end{tabular}

\section{Dynamic Tests on Wall Panels}

In the final stage of investigation, dynamic tests for real size wall panels of the wooden frame house were carried out for two variants of skeleton filling. 


\subsection{Experimental Setup}

The specially designed experimental setup was used to perform the tests (see Figures 15 and 16). It was constructed using a steel frame with dimensions of $300 \mathrm{~cm}$ by $50 \mathrm{~cm}$ that was fixed to the floor slab. The additional mounting socket, with dimensions of $150 \mathrm{~cm}$ by $60 \mathrm{~cm}$, was welded to the main frame to be used for installation of the wall panels (Figure 17). The dynamic actuator Parker ETB125, with the displacement range of $\pm 25 \mathrm{~cm}$, peak acceleration of $10 \mathrm{~m} / \mathrm{s}^{2}$ and maximum force of $45 \mathrm{kN}$ was installed on one side of the frame (Figure 17). The parameters of the designed setup enabled destructive testing of wooden wall elements, being at the same time strictly adapted to the dimensions of the tested elements.

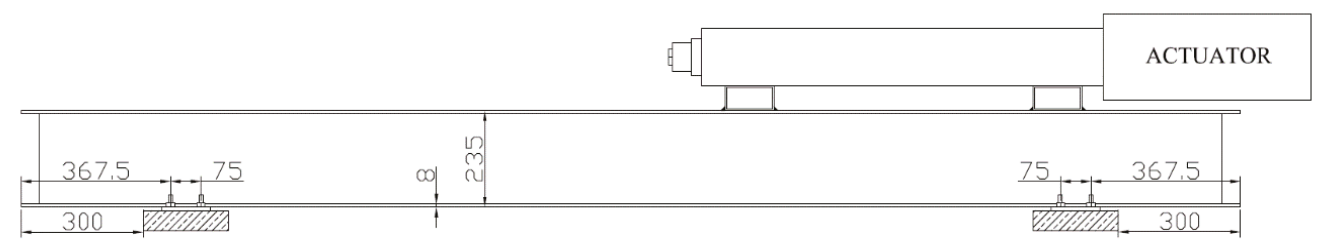

Figure 15. Sketch of experimental setup (side view of the main frame).

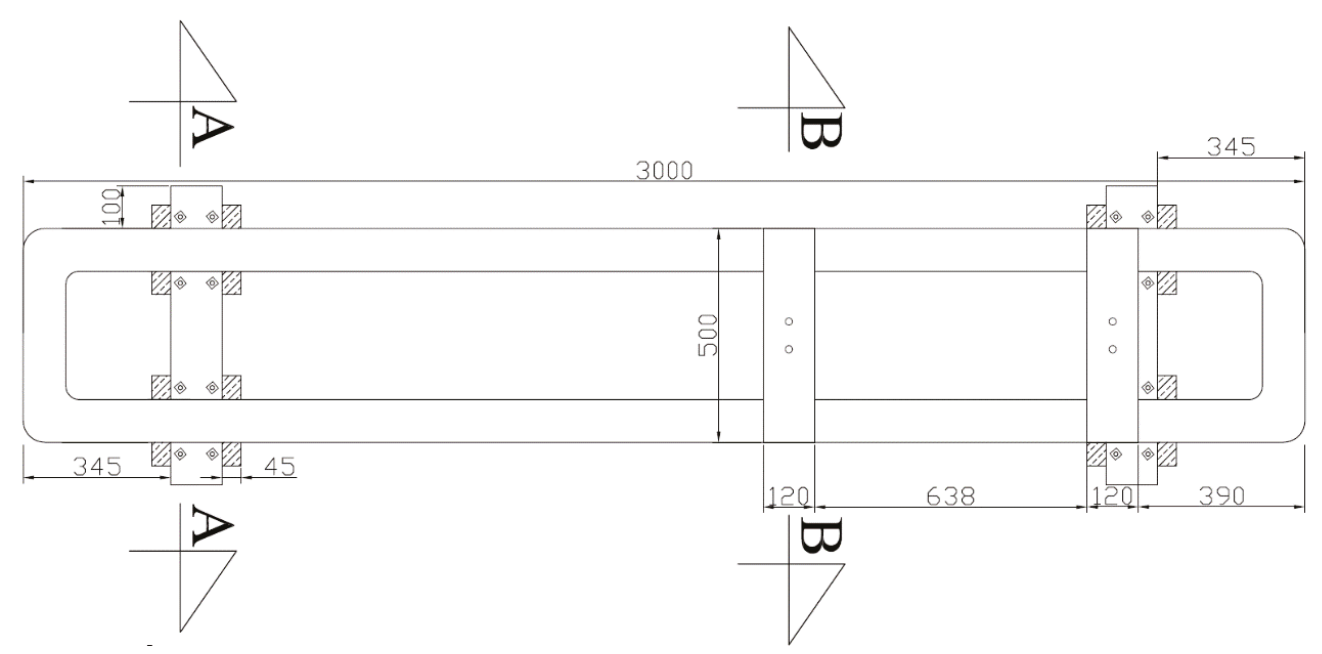

Figure 16. Sketch of experimental setup (top view of the main frame).

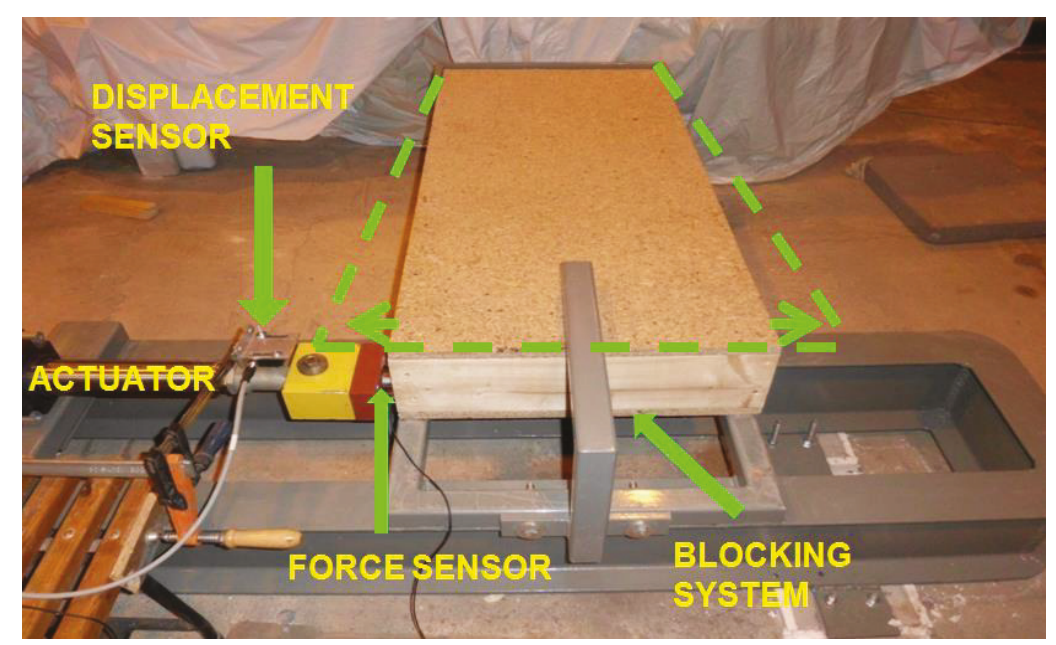

Figure 17. Experimental setup with installed panel. 
For the purpose of this study, a typical wooden frame house set of wall panels were prepared (see Figure 17). Using a modulus of $60 \mathrm{~cm}$ for the frame elements, each panel was constructed with C24 wood, filled either with mineral wool or polyurethane foam, and covered on both sides by OSB3 (Oriented Strand Board) sheaths. The dimensions of each panel were $129 \mathrm{~cm}$ in length and $60 \mathrm{~cm}$ in width. Wooden skeleton elements (posts and cap) were connected to each other using standard screws. Screws were also applied to connect the OSB3 sheaths and the skeleton itself. In this case, the connectors were used at the corners and along the length of the board at intervals of $10 \mathrm{~cm}$. Since the skeleton was covered by the single OSB3 boards on both sides (see Figure 17), there was no need to apply any connectors in the middle of the element. Material properties of different elements used in the panels are shown in Table 4.

Table 4. Material properties of different elements used in the wooden frame house wall panels.

\begin{tabular}{cccc}
\hline Element & Material & Density $\left[\mathrm{kg} / \mathrm{m}^{3}\right]$ & Elasticity Modulus [GPa] \\
\hline Frame & Wood of class C24 & 509.8 & $\begin{array}{c}11 \text {-along fibres } \\
0.37 \text {-across fibres }\end{array}$ \\
\hline Sheathing & OSB3 & 713.8 & $\begin{array}{c}1.98 \text {-along fibres } \\
4.93 \text {-across fibres }\end{array}$ \\
\hline Filling 1 & Mineral wool & 39 & 0.0005 \\
\hline Filling 2 & Polyurethane foam & 26 & 0.01 \\
\hline
\end{tabular}

One side of each of the tested panel was fixed to the experimental stand using $10 \mathrm{~mm}$ bolts, while the movement of the second side was allowed in the horizontal direction (buckling was prevented by special blocking system; see Figure 17).

\subsection{Results}

During experimental tests, both models were subjected to harmonic excitations. The tests were conducted at a frequency of $2 \mathrm{~Hz}$ for different values of displacement amplitude. Measurements were carried out with the sampling frequency of $500 \mathrm{kHz}$ using Alitec VIMEA VE 16BCA measuring system. The exerted force was recorded by a force sensor KMM40, working in the range of up to $50 \mathrm{kN}$, the accuracy class of 0.5 and sampling frequency of $200 \mathrm{~Hz}$ (according to the producer's specification). The resulting displacement was measured by a laser displacement sensor optoNCDT1302, working in the range of $\pm 100 \mathrm{~mm}$ with the micrometre accuracy and sampling frequency of $750 \mathrm{~Hz}$ (according to the producer's specification). The force sensor was mounted at the end of the actuator's moveable rod, while the displacement sensor was installed at the actuator's shaft (see Figure 17).

In the first stage of the tests, a wall panel with a skeleton filled with mineral wool was mounted on the stand. The results, in the form of representative hysteresis loops showing the relation between force and displacement, are presented in Figure 18. On this basis, the stiffness, $K$, and damping ratio, $\xi$, were calculated using the following formulas (see also Figure 19) [35]:

$$
\begin{gathered}
K=\frac{F\left(x_{e}\right)-F\left(-x_{e}\right)}{2 \cdot x_{e}} \\
\xi=\frac{\Delta W}{2 \pi \cdot F\left(x_{e}\right) \cdot x_{e}}
\end{gathered}
$$

The results are shown in Table 5. It should also be added that the tests for this element were destructive and could not be carried out for the amplitude of displacement larger than $28 \mathrm{~mm}$. For such amplitude, OSB3 sheathing began to detach from the skeleton, and connectors became loose leading to delamination of the panel (see Figure 20).

In the second stage of the tests, a wall panel filled with the polyurethane foam was installed on the stand. Then, the experiments were carried out for the same scheme as for the panel filled with the 
mineral wool. The results, in the form of representative hysteresis loops, are presented in Figure 21. On this basis, the stiffness and damping ratio were calculated using Equations (1) and (2) and the results are shown in Table 6. It should also be underlined that the structure of the element filled with the polyurethane foam passed all the tests without any damages. The only damages were concentrated in screws fixing the panel to the stand which were destroyed when the amplitude of displacement was larger than $50 \mathrm{~mm}$ (see Figure 22).

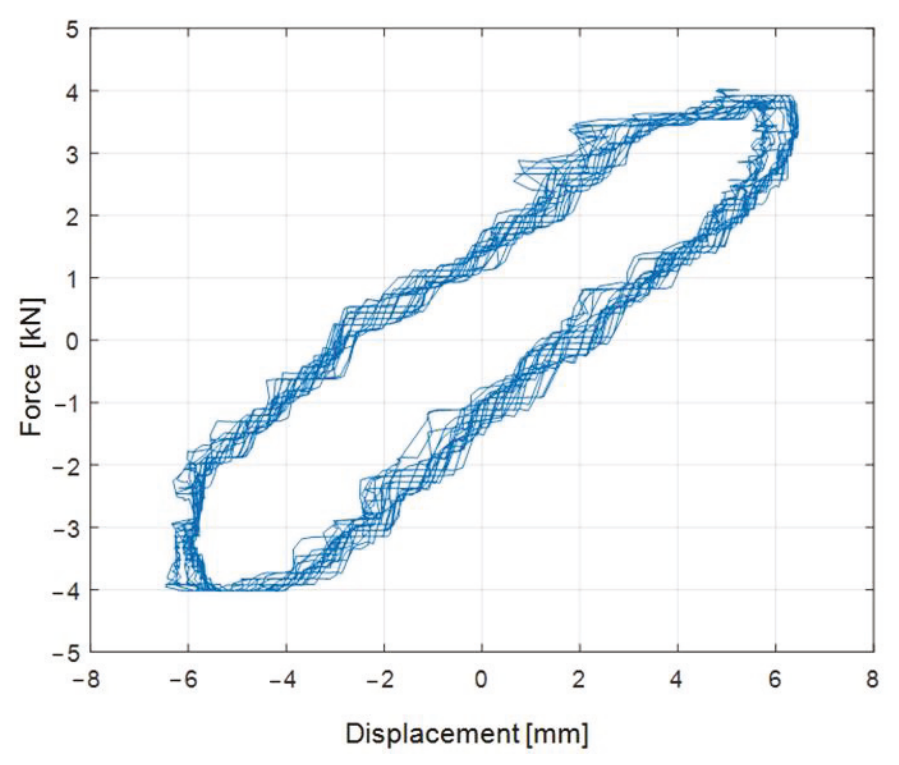

Figure 18. Hysteresis loops for the panel filled with mineral wool.

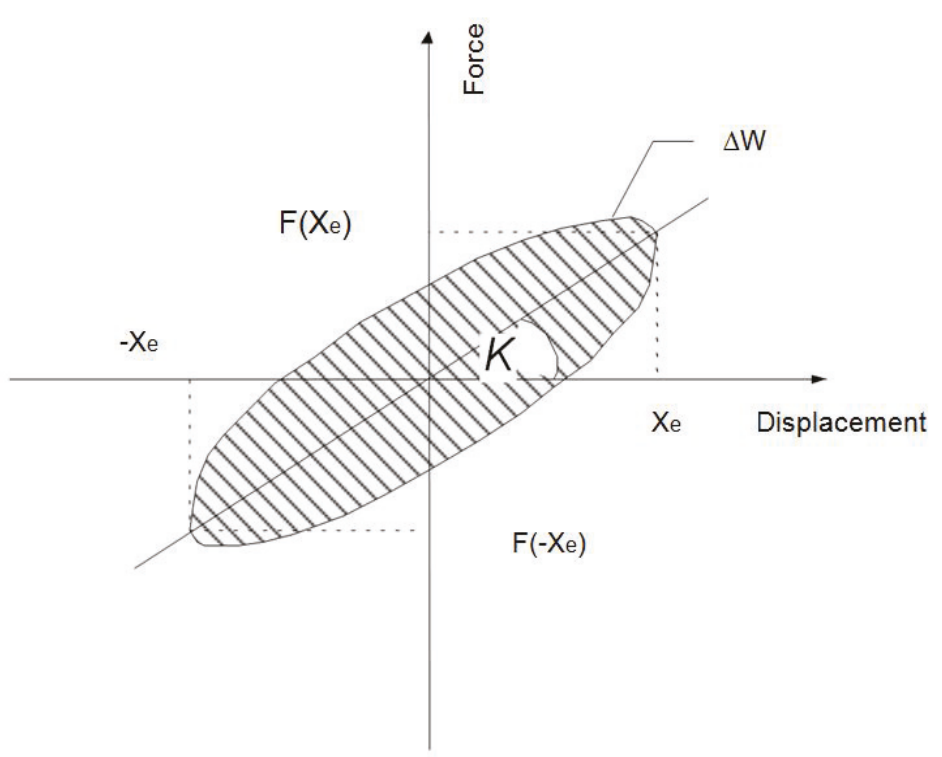

Figure 19. Hysteresis loop.

Table 5. Values of stiffness and damping ratio for the panel filled with mineral wool.

\begin{tabular}{ccc}
\hline Frequency [Hz] & Stiffness [kN/m] & Damping Ratio [\%] \\
\hline 2.0 & 416.66 & 17.09 \\
\hline
\end{tabular}



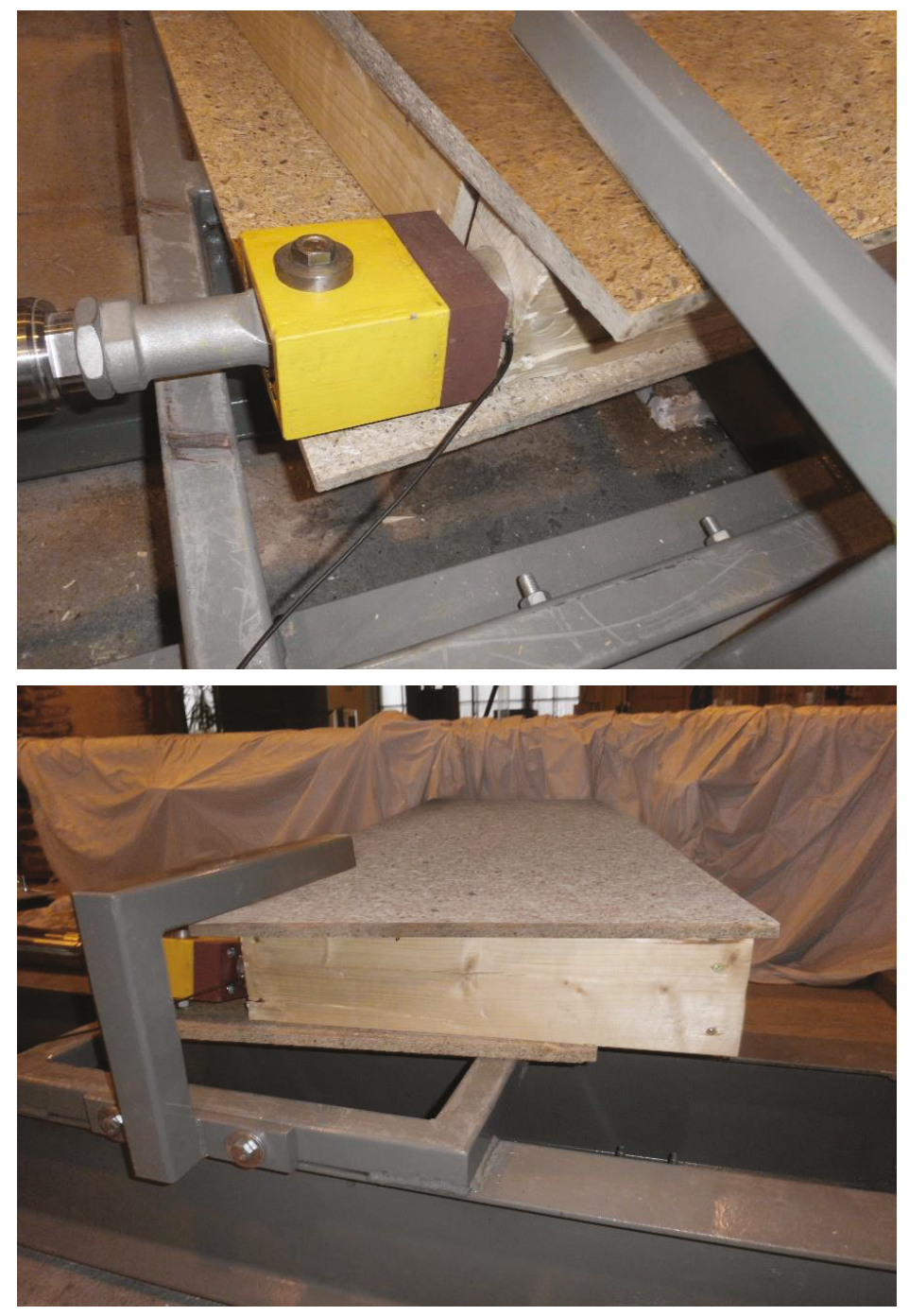

Figure 20. Panel filled with mineral wool after the tests.

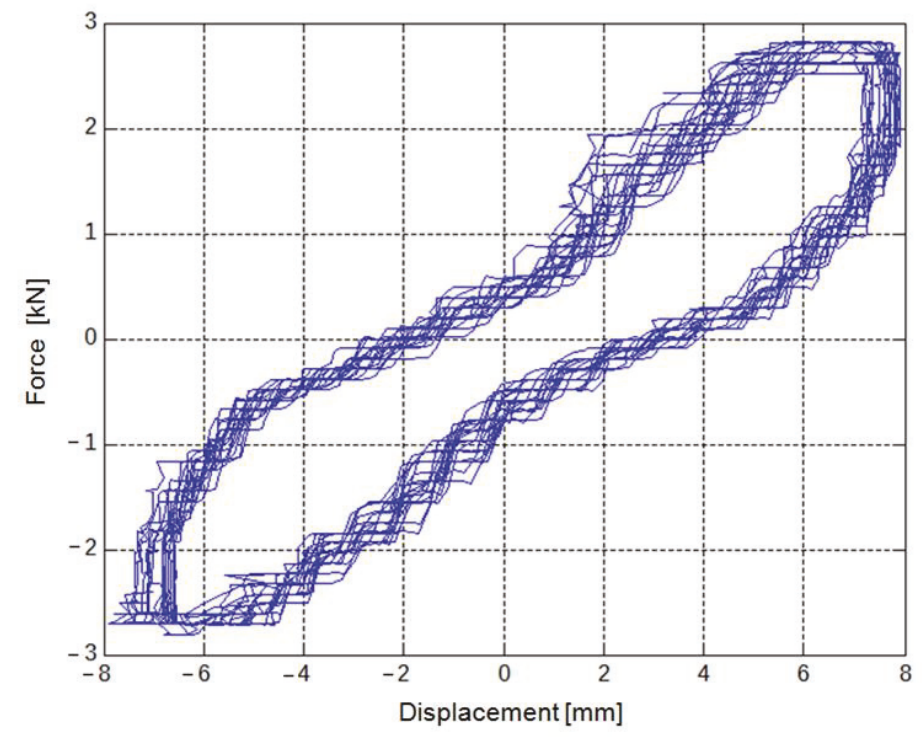

Figure 21. Hysteresis loops for the panel filled with polyurethane foam. 
Table 6. Values of stiffness and damping ratio for the panel filled with polyurethane foam.
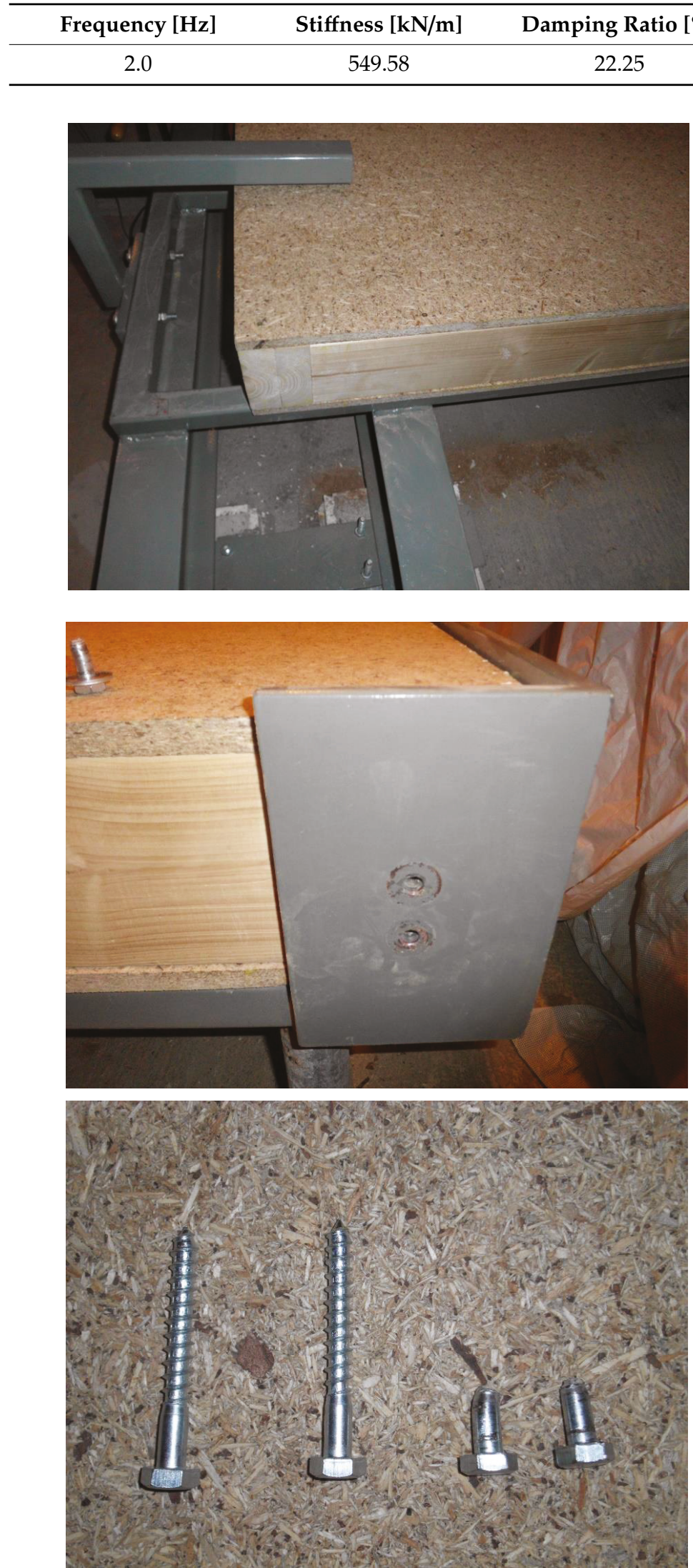

Figure 22. Panel filled with polyurethane foam after the tests. 


\section{Conclusions}

The dynamic response of wall panels of a wooden frame building with two variants of insulation, mineral wool and polyurethane foam, has been experimentally studied. Firstly, the static compression and tension tests were conducted for the polyurethane foam. Then, the DMA tests were carried out so as to determine the basic thermomechanical properties of both analyzed isolation materials (mineral wool and polyurethane foam). Finally, the elements of exterior walls with two types of thermal insulation were tested under harmonic excitation for different amplitudes of displacement. On this basis, stiffness and damping ratios were calculated.

Based on the results of the study, the following conclusions can be drawn:

- Polyurethane foam behaves in a highly nonlinear way both during static compression and tension.

- Storage modulus of the polyurethane foam is significantly larger in relation to the value obtained for the mineral wool.

- Loss modulus of the polyurethane foam is much larger compared to the modulus of the mineral wool.

- Polyurethane foam, as a material, is able to absorb a greater amount of energy. Comparing it to the mineral wool, it is a material with much better energy absorption capabilities.

- The use of polyurethane foam as thermal isolation leads to a substantial increase in stiffness and damping properties of wall panels, compared to the mineral wood.

- The panel filled with the polyurethane foam passed all the tests without any damages, whereas the tests for the panel with the mineral wood were destructive.

- The use of polyurethane foam caused the integration of individual elements of the panel allowing it to behave as one element, increasing its strength and spatial rigidity.

- Damping properties of the polyurethane foam contributed to an increase in the dynamic resistance of the panel, since larger amount energy could be dissipated.

Taking into account the above arguments, it is recommended to apply the polyurethane foam not only as an isolation material but also to increase the dynamic resistance of skeletal wooden structures. It can be used for newly constructed houses. It can also be applied in the case of existing wood-frame buildings since replacing the mineral wool with the polyurethane foam is relatively easy. The results of the investigation shown in this paper indicate that such an approach would be a very effective method of increasing the dynamic resistance of existing structures. Moreover, the polyurethane foam is a material widely available and increasingly used in civil engineering. It is also a relatively inexpensive and durable material compared to other insulation materials, which also makes it very attractive.

Author Contributions: Conceptualization, M.S. and R.J.; data curation, M.S.; formal analysis, M.S., W.M., and R.J.; methodology, M.S. and R.J.; writing—original draft, M.S. and W.M.; writing—review and editing, R.J.

Funding: This research received no external funding.

Acknowledgments: The authors would like to thank Maciej Wysokiński from STOLKAL Company for supplying the specimens used in the tests, as well as Bohdan Kowalewski and Łukasz Piszczyk for their help during the tests.

Conflicts of Interest: The authors declare no conflict of interest.

\section{References}

1. Migda, W.; Jankowski, R. An approach for the response of buildings subjected to impact load after soft-story failure due to earthquake excitation. Shock Vib. 2013, 20, 681-692. [CrossRef]

2. Jankowski, R. Pounding between superstructure segments in multi-supported elevated bridge with three-span continuous deck under 3D non-uniform earthquake excitation. J. Earthq. Tsunami 2015, 9, 1550012. [CrossRef]

3. Jankowski, R.; Mahmoud, S. Linking of adjacent three-storey buildings for mitigation of structural pounding during earthquakes. Bull. Earthq. Eng. 2016, 14, 3075-3097. [CrossRef]

4. Li, X.; Wang, J.; Bao, Y.; Chen, G. Cyclic behavior of damaged reinforced concrete columns repaired with high-performance fiber-reinforced cementitious composite. Eng. Struct. 2017, 136, 26-35. [CrossRef] 
5. ECS. Eurocode 8: Design Provisions for Earthquake Resistance of Structures; European Committee for Standardization: Brussels, Belgium, 1998.

6. Teng, J.G.; Yu, T.; Fernando, D. Strengthening of steel structures with fiber-reinforced polymer composites. J. Constr. Steel Res. 2012, 78, 131-143. [CrossRef]

7. Linghoff, D.; Haghani, R.; Al-Emrani, M. Carbon-fibre composites for strengthening steel structures. Thin Walled Struct. 2009, 47, 1048-1058. [CrossRef]

8. Kim, D.H.; Moon, D.Y.; Kim, M.K.; Zi, G.; Roh, H. Experimental test and seismic performance of partial precast concrete segmental bridge column with cast-in-place base. Eng. Struct. 2015, 100, 178-188. [CrossRef]

9. Shrive, N.G. The use of fibre reinforced polymers to improve seismic resistance of masonry. Constr. Build. Mater. 2006, 20, 269-277. [CrossRef]

10. Kwiecień, A. Strengthening of masonry using natural fibers bonding with highly deformable adhesives. J. Eng. Technol. 2015, 3, 103-114.

11. Falborski, T.; Jankowski, R.; Kwiecień, A. Experimental study on polymer mass used to repair damaged structures. Key Eng. Mater. 2012, 488-489, 347-350. [CrossRef]

12. Kasal, B.; Polocoser, T.; Guindos, P.; Urushadze, S.; Pospisil, S.; Heiduschke, A.; Ruther, N.; Zembaty, Z. High performance composite-reinforced earthquake resistant buildings with self-aligning capabilities. Geotechnical. Geol. Earthq. Eng. 2015, 235, 359-372.

13. Meng, W.; Khayat, K.H.; Bao, Y. Flexural behaviors of fiber-reinforced polymer fabric reinforced ultra-high-performance concrete panels. Cem. Concr. Compos. 2018, 93, 43-53. [CrossRef]

14. Meng, W.; Khayat, K.H. Development of stay-in-place formwork using GFRP reinforced UHPC elements. In Proceedings of the First International Interactive Symposium on UHPC, Des Moines, IA, USA, 18-20 July 2016; pp. 1-9.

15. Bedon, C.; Amadio, C. Enhancement of the seismic performance of multi-storey buildings by means of dissipative glazing curtain walls. Eng. Struct. 2017, 152, 320-334. [CrossRef]

16. Toratti, T. Design guidance on Eurocode 8 for practicing engineers for timber structures. In International Workshop on Earthquake Engineering on Timber Structures; University of Coimbra: Coimbra, Portugal, 2006; pp. 55-70.

17. Toratti, T. Seismic Design of Timber Structures; FEMA: Espoo, Finland, 1994.

18. Liang, H.; Wen, Y.-K.; Foliente, G.C. Damage modeling and damage limit state criterion for wood-frame buildings subjected to seismic loads. J. Struct. Eng. 2011, 137, 41-48. [CrossRef]

19. Heiduschke, A.; Kasal, B.; Haller, P. Shake table tests of small-and full-scale laminated timber frames with moment connections. Bull. Earthq. Eng. 2009, 7, 323-339. [CrossRef]

20. Filiatrault, A.; Christovasilis, I.P.; Wanitkorkul, A.; Wan de Lindt, J.W. Experimental seismic response of a full-scale light-frame wood building. J. Struct. Eng. 2010, 136, 246-254. [CrossRef]

21. Dujic, B.; Zarnic, R. Study of lateral resistance of massive X-lam wooden wall system subjected to horizontal loads. In International Workshop on Earthquake Engineering on Timber Structures; University of Coimbra: Coimbra, Portugal, 2006; pp. 97-104.

22. Fournely, E.; Lamadon, T. Design detailing for earthquake engineering application for timber structures. In International Workshop on Earthquake Engineering on Timber Structures; University of Coimbra: Coimbra, Portugal, 2006; pp. 71-80.

23. Vessby, J. Analysis of Shear Walls for Multi-Storey Timber Buildings; Linnaeus University Dissertations: Växjö, Sweden, 2011.

24. González Fueyo, J.L.; Dominguez, M.; Cabezas, J.A.; Rubio, M.P. Design of connections with metal dowel-type fasteners in double shear. Mater. Struct. 2009, 42, 385-397. [CrossRef]

25. Echavarría, C.; Salenikovich, A. Analytical model for predicting brittle failures of bolted timber joints. Mater. Struct. 2009, 42, 867-875. [CrossRef]

26. Miller, J.F.; Schmidt, R.J.; Bulleit, W.M. New yield model for wood dowel connections. J. Struct. Eng. 2010, 136, 1255-1261. [CrossRef]

27. Germano, F.; Metelli, G.; Giuriani, E. Experimental results on the role of sheathing-to-frame and base connections of a European timber framed shear wall. Constr. Build. Mater. 2015, 80, 315-328. [CrossRef]

28. Gattesco, N.; Boem, I. Seismic performances and behavior factor of post-and-beam timber buildings braced with nailed shear walls. Eng. Struct. 2015, 100, 674-685. [CrossRef]

29. Nitka, W. My Wooden House; National Forest Information Centre: Warsaw, Poland, 2010. 
30. Donovan, T.; Memari, M. Feasibility study of determination of seismic performance factors for structural insulated panels. J. Archit. Eng. 2015, 21, 1-9. [CrossRef]

31. Kasal, B.; Heiduschke, A.; Haller, P. Analysis of wood-composite laminated frames under dynamic loads-Analytical models and model validation. Part I: Connection Model. Prog. Struct. Eng. Mater. 2006, 8, 103-110.

32. Szczepański, M.; Migda, W.; Jankowski, R. Modal analysis of real timber frame houses with different insulation materials. Adv. Sci. Technol. Res. J. 2016, 10, 215-221. [CrossRef]

33. Szczepański, M.; Migda, W.; Jankowski, R. Increasing the seismic resistance of wood-frame buildings by applying PU foam as thermal insulation. Period. Polytech. Civ. Eng. 2019, 63, 480-488.

34. Kumar, A.; Gupta, R.K. Fundamentals of Polymer Engineering; Marcel Dekker: New York, NY, USA, 2003.

35. Falborski, T.; Jankowski, R. Advanced hysteretic model of a prototype seismic isolation system made of polymeric bearings. Appl. Sci. 2018, 8, 400. [CrossRef]

(C) 2019 by the authors. Licensee MDPI, Basel, Switzerland. This article is an open access article distributed under the terms and conditions of the Creative Commons Attribution (CC BY) license (http://creativecommons.org/licenses/by/4.0/). 